\title{
A unique case of mandibular osteomyelitis arising from tooth germ infection in a 7,000-year-old infant from Siberia
} Andrea L. Waters-Rist* Faculty of Archaeology, Leiden University, Leiden, The Netherlands, PO Box 9515, 2300 RA.

Keywords: Paleopathology, Tooth Calcification, Bone Infection, Oral Microbiology, Osteomyelitis, Periostitis, Central Asia

ABSTRACT Excavations from a 7,000-year-old mortuary site in the Lake Baikal region of Siberia, Russian Federation, revealed an infant with osteomyelitis of the mandible. The lesion exhibits deformation of the anterior mandibular base, an extra-oral cloaca, and new periosteal bone layers on the corpus. Entry of oral microorganisms was likely via the deciduous left canine, with infection

Knowledge of diseases is furthered by their evidence in ancient peoples. Osteomyelitis of the mandible arising from a tooth germ infection is relatively rare in modern populations (Baltersperger and Eyrich, 2009) and is not widely reported in paleopathology literature. This case report presents what is argued to be a 7,000-year-old case of mandibular osteomyelitis with accompanying new periosteal bone in an infant from a mortuary site named Shamanka II in south-central Siberia, Russian Federation. The lesion's hypervascular appearance is rather distinctive, with a small cloaca and extensive, irregular periosteal bone deposits on the mandibular corpus. Osteomyelitis of the jaws differs from that of the long bones because of the former's unique tooth bearing function and connection to the oral cavity and periodontal membrane. Thus, local immunological and microbiological factors are important in the disease's etiology and pathogenesis (Baltensperger and Eyrich, 2009; Slootweg, 2010). Immature teeth are especially susceptible to infection because of incomplete root formation with open apices and large canal sizes (Huang, 2009). Further, because common nonpathogenic oral microorganisms have the potential to cause infection (Willet et al., 1991), osteomyelitis is possible even in the absence of carious or periodontal lesions, as is argued for this case. When considering paleopathology of the jaws it should be kept in mind that oral microbes have great antiquity and thus the potential for an endodontic infection route has been present for many millennia. Therefore, this case report is useful for dental anthropologists and paleopatholo- then concentrated around the forming permanent canine tooth germ. This infection route is not widely documented in paleopathology and the pathogenicity of oral microorganisms is discussed. This unique case is one of the oldest examples of infant osteomyelitis of the jaws, adding to our understanding of the antiquity and development of infectious diseases in humankind.

gists for several reasons: a) in presenting an ancient case of mandibular osteomyelitis of unique appearance, b) in demonstrating the presence of the tooth germ infection route, even in the absence of carious and periodontal infection, and c) in illustrating the importance of considering the pathogenicity of otherwise normal oral microorganisms.

\section{MATERIALS}

The infant, numbered 66-2, was excavated from an Early Neolithic mortuary site located at the southern end of Lake Baikal, Siberia, Russian Federation (Fig. 1). Preservation and completeness are very good, with the only bones missing being the scapulae, ischium, and pubis. Shamanka II has been radiocarbon dated to 7,0006,100 calibrated years before present (calBP), a period when these hunter-fisher-gatherers began establishing large formal burial areas for their dead (Bazaliiskii, 2010; Weber et al., 2010). Diets were predominately composed of lake fish (Katzenberg et al., 2010). Individual 66-2 was interred beside a young adult female, numbered 66 -1 , both in an extended supine position with no evidence of post-depositional disturbance (Fig. 2). Individuals 66-1 and 66-2 are radiocarbon dated to $6931+/-39$ and $6890+/-40$ calBP respectively, suggesting that they were buried at the same time (Weber et al., 2010). Future ancient DNA analysis may determine the infant's sex and relation to the adult female.

Correspondence: Andrea L. Waters-Rist, e-mail:

a.l.waters@arch.leidenuniv.nl

Telephone number: +31 (0)71-527-1685 
The following is a description of the mandibular lesion in individual 66-2 (Figs. 3, 4 and 5): The anterior aspect of the mandibular corpus, bracketed by the canines, and extending from the alveolar margin to the inferior margin of the body, has new periosteal bone laid down in roughly horizontal bands, typical of hypervascular lesions (Fig. 3). Both fiber (woven) and lamellar bone are evident. There is some minor, largely resorbed pitting in this area. All this suggests that an episode (or episodes) of healing occurred, but that the lesion was active at the time of death. Slightly left of the mandibular apex, along the inferior border, a small opening is visible, that on radiograph is confirmed to be a cloaca originating at the inferior margin of the forming permanent canine (in the cap stage of development) socket (Fig. 5). The inferior border of the mandible is uneven from the right central incisor to just past the left deciduous canine socket. On the corpus, on either side of the mental eminence, there is increased porosity without much new bone formation. The pores appear to have relatively smooth margins and bone in this area is generally even.

The individual had no other pathological lesions on the elements that were recovered, most notably the maxilla. Note that there is minor post -mortem damage to the anterior alveolar margins of the canine sockets in the form of a small amount of breakage and flaking of the thin bony plates. Otherwise, there are no indications of taphonomic changes to the mandible - no bone distortion, discolouration, fracture, or cortical erosion. The anterior aspect of the mandible is very well-preserved and a considerable amount of morphological detail can be observed. This, combined with the fact that within the lesion new bony deposits, a cloaca, and areas of healing are clearly evident, confirm that the lesion is not the result of taphonomic processes.

\section{METHODS}

The age-at-death of individual 66-2, based on tooth formation and eruption standards, is estimated at 21+/-6 months (1.75 years) (Moorrees et al., 1963a and b; Liversidge and Molleson, 2004). This age range should encapsulate any age difference resulting from the use of standards derived from populations of different ancestry (i.e. European vs. Asian ancestry; Liversidge, 2003). None of the teeth in individual 66-2 are carious (Fig. 4), and there is no loss of alveolar margin height associated with periodontal disease in the mandible or maxillae. None of the observable deciduous teeth, nor the forming permanent first molars, have hypoplastic enamel defects associated with periods of non-specific stress such as malnutrition or disease.

A number of classification systems have been established for the distinct clinical entity of osteomyelitis of the jaws (i.e. Cierny et al., 1985) of which the Zurich system, based primarily on clinical appearance and radiological features, will be followed herein (see Baltensperger and Eyrich, 2009 for a thorough review). Radiographs were taken using the NOMAD Pro handheld X-ray system.

\section{RESULTS}

\section{Differential Diagnosis}

There is a huge variety of pathological lesions that occur in the mandible that can overlap considerably in morphological, radiological, and histological appearance, often making diagnosis difficult even in clinical settings (Slootweg, 2010). In this case the differential diagnosis is heavily based upon evidence of endodontic infection, via the cloaca originating from the left deciduous and permanent mandibular canines, as well as a lack of evidence for trauma. The route of infection would have been the left mandibular deciduous canine, which is linked to the forming permanent canine via the gubernacular canal which connects the shared tooth sac, facilitating the transfer of infectious microorganisms (Rodriguez -Cordeiro and de Carvalho Rocha, 2005).

Due to differences in the macroscopic and radiologic appearance of the following conditions they have been ruled out of the differential diagnosis: osteosarcoma, Ewing's sarcoma, fibrous dysplasia, and periapical osseous dysplasia. In short, there is no localized tumour-like permeative lytic lesion with a radiological appearance that is 'moth-eaten' or 'sun-burst' as is typical of neoplastic diseases, the radiograph shows no evidence of the presence of fibrous tissue as in the extremely rare fibrous dysplasia, and there is no involvement of the tooth roots or masses of cementum resulting in multiple, circumscribed, non-corticated radiolucencies as in periapical osseous dysplasia, which also differs in that its mean age of onset is after 30 years. 


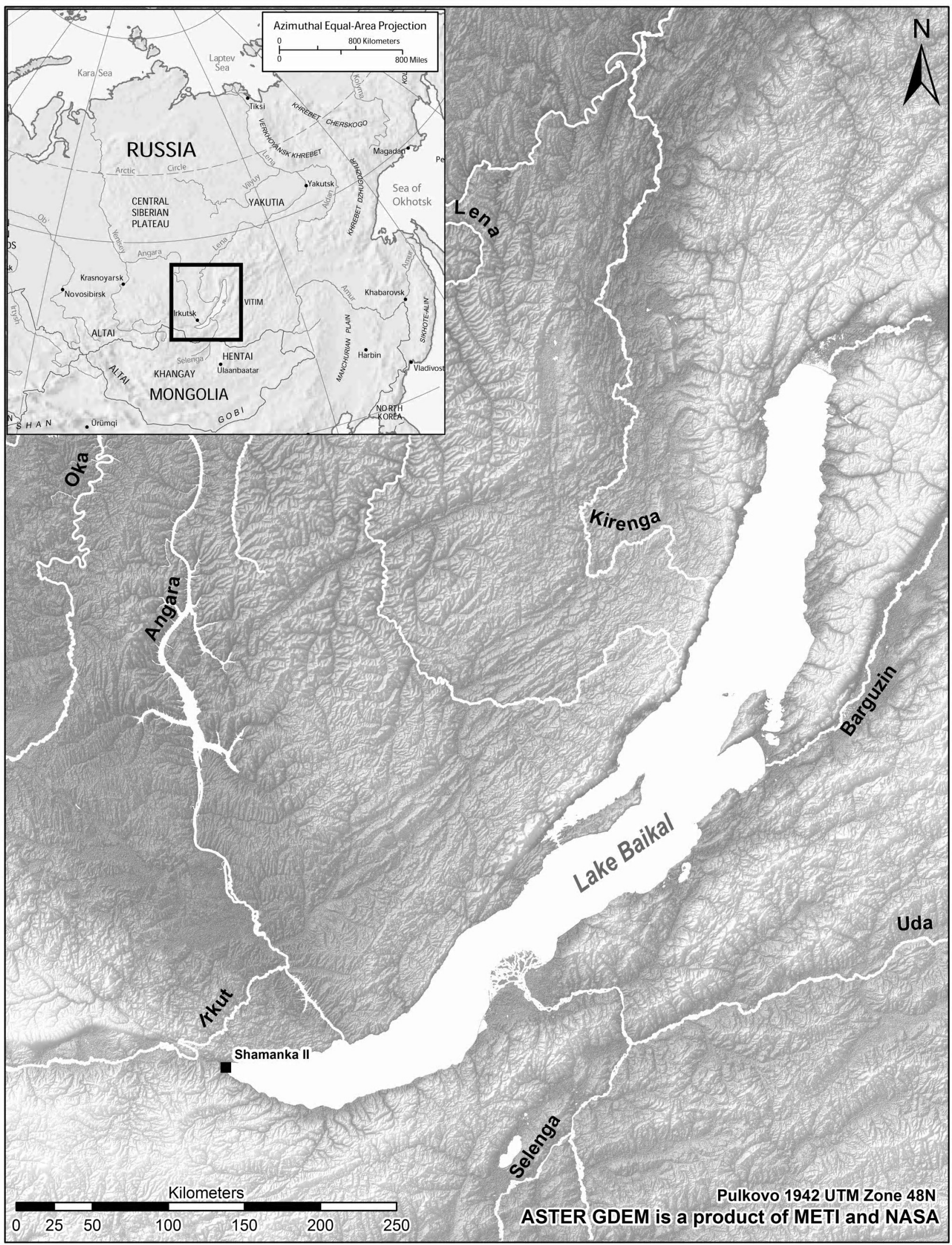

Fig. 1. Lake Baikal, Siberia, and the location of the mortuary site of Shamanka II. 
Four additional diseases, described below, are considered more likely options in the differential diagnosis: tuberculosis, noma (gangrene of the face), infantile cortical hyperostosis (Caffey's disease), and periostitis ossificans.

Tuberculosis (TB) is caused by the Myobacterium tuberculosis complex, which is estimated to have appeared 15,000 to 20,000 years ago (Kapur et al., 1994), with an early example from a 9,000year-old agricultural village in Israel (Hershkovitz et al., 2008). Its prevalence in humans increased with animal domestication, eventually becoming endemic in large, sedentary populations across the world. TB osteomyelitic lesions are most common in the spine, hip and knees, with bacilli localized especially in areas of hematopoietic marrow (Aufderheide and Rodriquez-Martin, 1998; Roberts and Manchester, 2010). TB rarely causes cranial lesions, but in those rare cases where it does, it is often in a child (Thijn and Steensma, 1990). However, lesions usually occur in the cranial vault (because of bacilli localization in the diploe), sometimes with hypervascular lesions on the endocranial surface (Mukherjee et al., 2002; Pálfi et al., 2012), and children are more likely to have lesions in several bones (Messner, 1987; Gupta and Singh, 2007), both features lacking in this case. Gadgil et al. (2012) estimate that less than two percent of the roughly five to seven percent of tuberculosis cases that result in skeletal lesions are located in the mandible $(<0.10$ to $0.14 \%)$ (also see Erasmus et al., 1998). Ortner (2003) notes that TB lesions in the mandibulae of children are located near the angle, again dissimilar to the lesion in question. Given the low population density, lack of animal domestication, and lack of evidence for TB in any other Cis-Baikal skeletons from this time period, it is very unlikely the lesion was a result of TB. TB is also marked by more of a destructive (lytic) than proliferative process (i.e., see example in Lewis 2011: 18; Roberts and Manchester, 2010) which does not fit the appearance of the lesion in individual 66-2 with its extensive periostitis and single, small cloaca.

Noma (also known as cancrum oris) results from gangrenous sores in the gingiva caused by a range of fusospirochetal bacteria species (Enwonwu et al., 2000; Baratti-Meyer et al., 2003). It frequently occurs adjacent to carious or periodontal lesions, in malnourished or ill children,

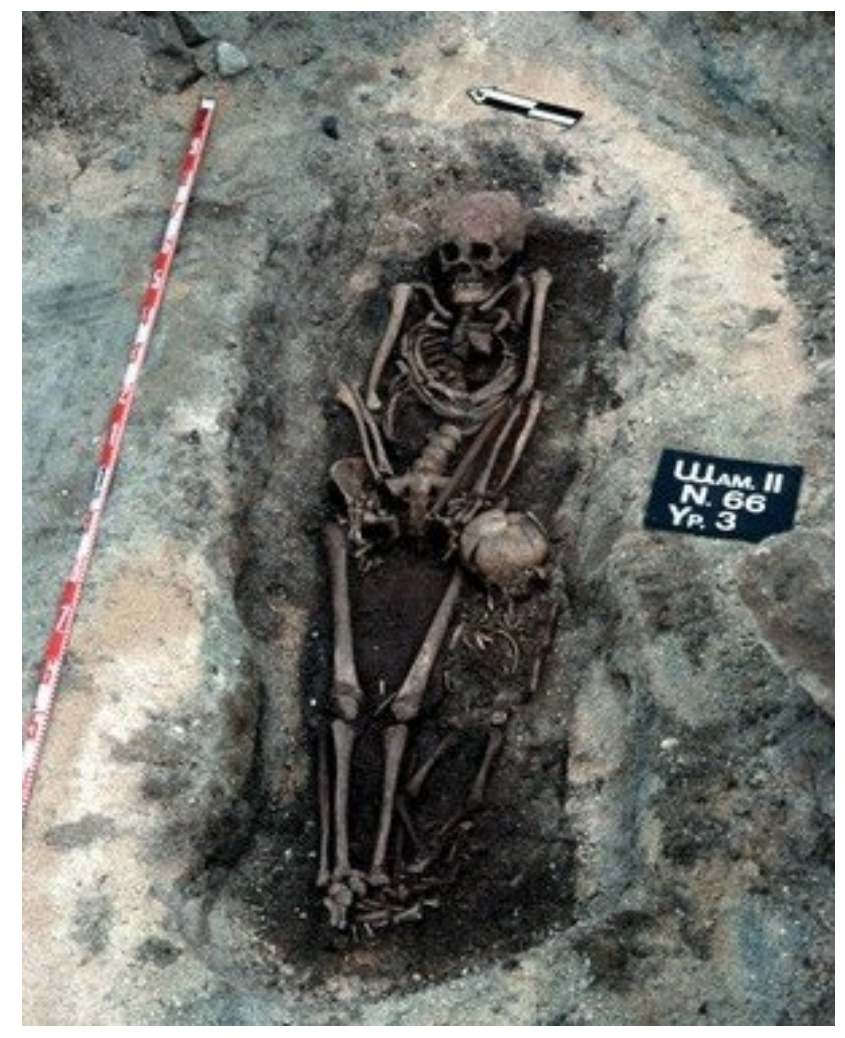

Fig. 2. Grave 66, Shamanka II. Individual 66-1 is a 25 to 35 -year-old female; Individual $66-2$ is a 1.75year-old infant.

most often between the ages of two to six years, resulting in severe disfigurement with a high mortality rate (Enwonwu et al., 2000). It is unlikely the lesion in individual 66-2 is the result of noma because noma spreads quickly, causing extensive jaw and and facial destruction, and lacks a bone-producing aspect. In addition, osseous noma lesions most commonly originate in the molar area, and sequestrum almost always result, which do not fit the appearance of the lesion in question.

Infantile cortical hyperostosis (Caffey's disease) is a rare inflammatory disease characterized by soft-tissue swelling usually with accompanying periosteal hyperostosis, most often occurring in the mandible, but also in the clavicles, ribs, scapulae and/or long bones (Caffey and Silverman, 1945). It is most often found in infants less than six months of age, after which it frequently spontaneously resolves with complete recovery by two to three years of age (MacLachlan et al., 1984). While age of occurrence is not that dissimilar, lesions usually occur at the 
angle or ramus of the mandible and are characterized by new lamellae layers with an onionskin appearance (see Lewis and Gowland (2009) for archaeological examples), which is different from the lesion in individual 66-2. As well, because infantile cortical hyperostosis does not have a purulent aspect (which would cause a cloaca), it is not a good diagnostic fit for this lesion.

Finally, periostitis ossificans (also called Garre's osteomyelitis) is a rare non-purulent form of osteomyelitis with intense proliferation of the periosteum resulting in new bone formation, often with new lamellae layers giving an onionskin appearance (Felsburg et al., 1990; Belli et al., 2002) that can affect an extensive part of the jaw. It usually affects individuals before the age of 25, primarily children and adolescents (Felsburg et al., 1990; Belli et al., 2002). The lateral, toothbearing aspects of the mandible (usually below first molar) are most affected, but important for this diagnosis is that it rarely crosses midline. It is similar to infantile cortical hyperostosis in that purulent discharge is rare, meaning cloacae are unlikely (although see Gonclaves et al., 2002), making this diagnosis a poor fit to the lesion morphology of individual 66-2.

Thus, none of the aforementioned diseases are a good match for the appearance of the lesion in individual 66-2. Rather, the disease classification that fits most closely is osteomyelitis with proliferative periostitis. Osteomyelitis is an infection of the bone by purulent microorganisms (Resnick, 2002) beginning in the medullary cavity and Haversian systems and extending to involve the periosteum. The Zurich system classifies it into three major categories: 1) acute osteomyelitis, 2) secondary chronic osteomyelitis, and 3) primary chronic osteomyelitis. Categories 1 and 2, acute and chronic, are the same disease separated by an arbitrary time limit of four weeks after disease onset, as recommended by Marx (1991) and Mercuri (1991), and subsequently widely adopted by clinicians (i.e. Lew and Waldvogel, 2004). The third category, primary chronic osteomyelitis refers to a rare, nonsuppurative, chronic inflammation of the jaws of unknown cause and thus does not apply to this case. The extent of the lesion in individual 66-2 suggests the disease had

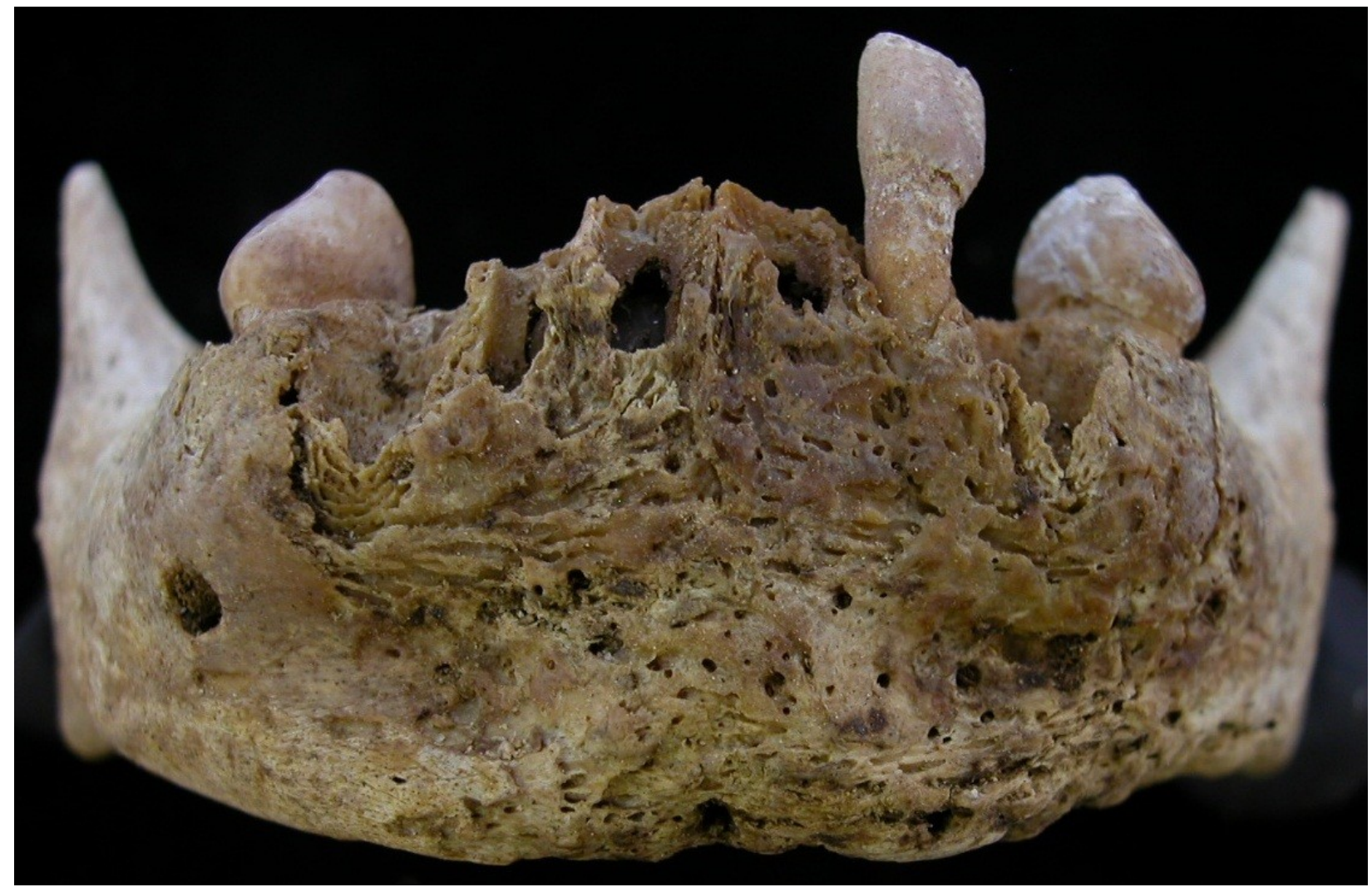

Fig. 3. Anterior view of the mandible of Individual 66-2, Shamanka II, showing pathological lesion. 


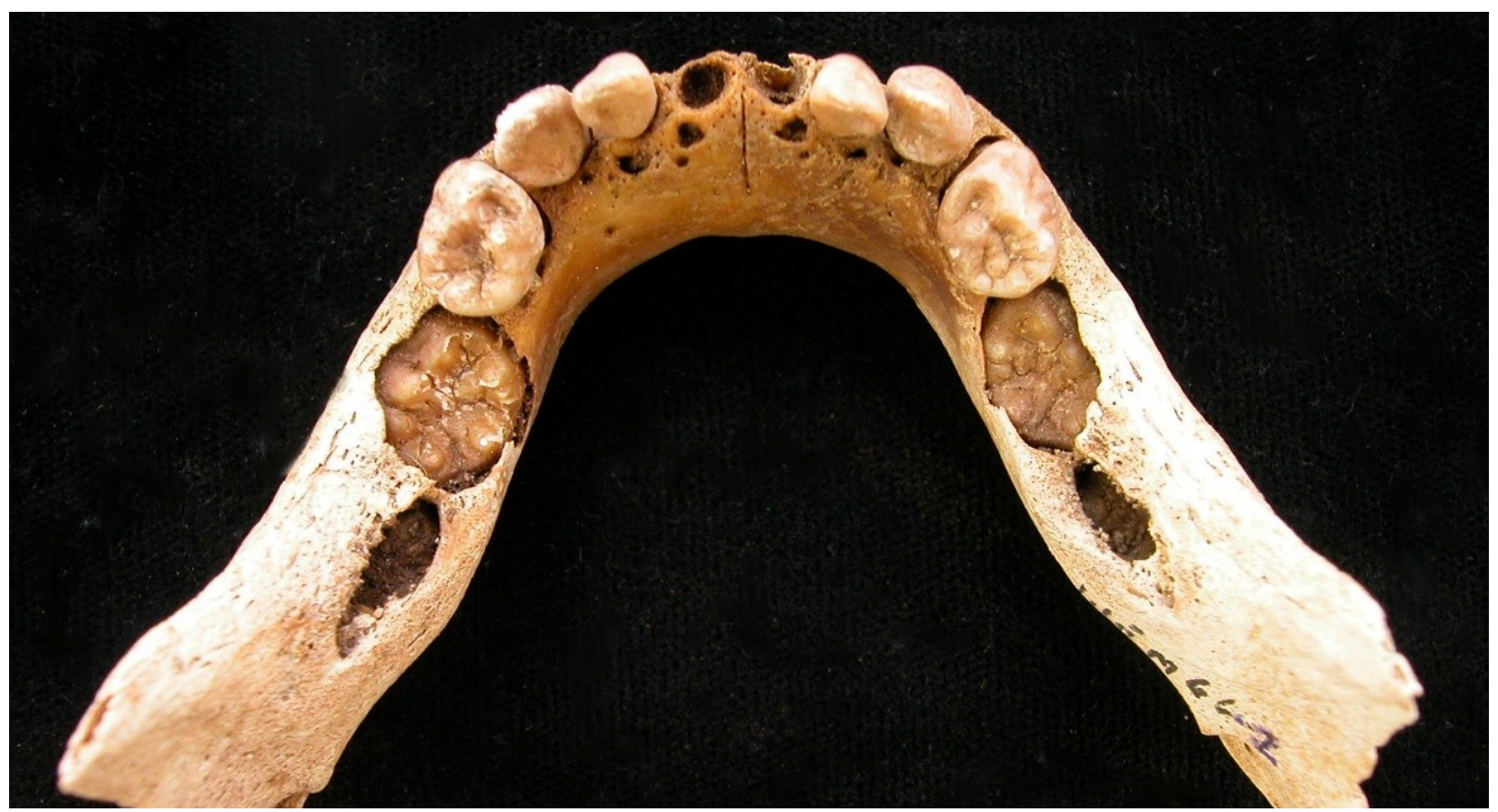

Fig. 4. Superior view of the mandible of Individual 66-2, Shamanka II, showing status of dental eruption and the lack of carious or periodontal lesions.

entered a chronic phase (category 2). Prior to antibiotic treatment, mandibular osteomyelitis usually presented in the secondary chronic phase (Wilensky, 1932). Compromised local blood supply is an important factor in the establishment of osteomyelitis, since immune cells and oxygen cannot reach the infected area facilitating the growth and spread of microorganisms, especially anaerobes (Bruder et al., 2009). The acute to chronic phase is often due to microorganism biofilm colonization of necrotic bone leading to inflammation and a suppurative response (Bruder et al., 2009).

Age does not have a major role on the incidence of maxillary osteomyelitis (Baltensperger et al., 2004).

Chronic osteomyelitis of the skull is found most often in the mandible, even in comparison to the maxilla (see Baranoff, 1934). The lesion is usually focused in one anatomical site (Baltensperger et al. 2004; Lew and Waldvogel, 2004), a point which differs to a certain extent from the appearance of the lesion in individual 66-2, although in this case it is mostly the periosteal reactive bone that is non-localized with the deformation of the inferior border of the mandible located mostly on the left side nearest the cloaca. The partially bilaterally symmetrical appearance of the lesion in individual 66-2 is suggested to have occurred be- cause the location of the cloaca terminus is close to the midline (its direction is angled from the left canine socket to the area under the left central incisor) and exudate discharge would have resulted in substantial periosteal elevation (see below) that allowed the spread of microorganisms. As to why the infection spread across the midline and became secondarily situated around the right incisor and canine sockets (as opposed to spreading posteriorly towards the left molars), possibly the active eruption of the deciduous canines caused antecedent loosening of the periosteum that presented little barrier against infiltrate spread. It is only speculative, but the periosteum around the left first molar may have been more firmly attached to the bone thereby presenting a more effective barrier because that area underwent tooth eruption at an earlier age. Radiologically there is no evidence of a sequestrum, which may be due to the individual's young age precluding development, however Ortner (2003) notes that osteomyelitis of the mandible rarely results in the formation of a sequestrum. Thus, these factors are congruent with a diagnosis of osteomyelitis for individual 66-2.

The presence of new periosteal bone is also consistent with a diagnosis of osteomyelitis, as it occurs relatively commonly as a result of perio- 


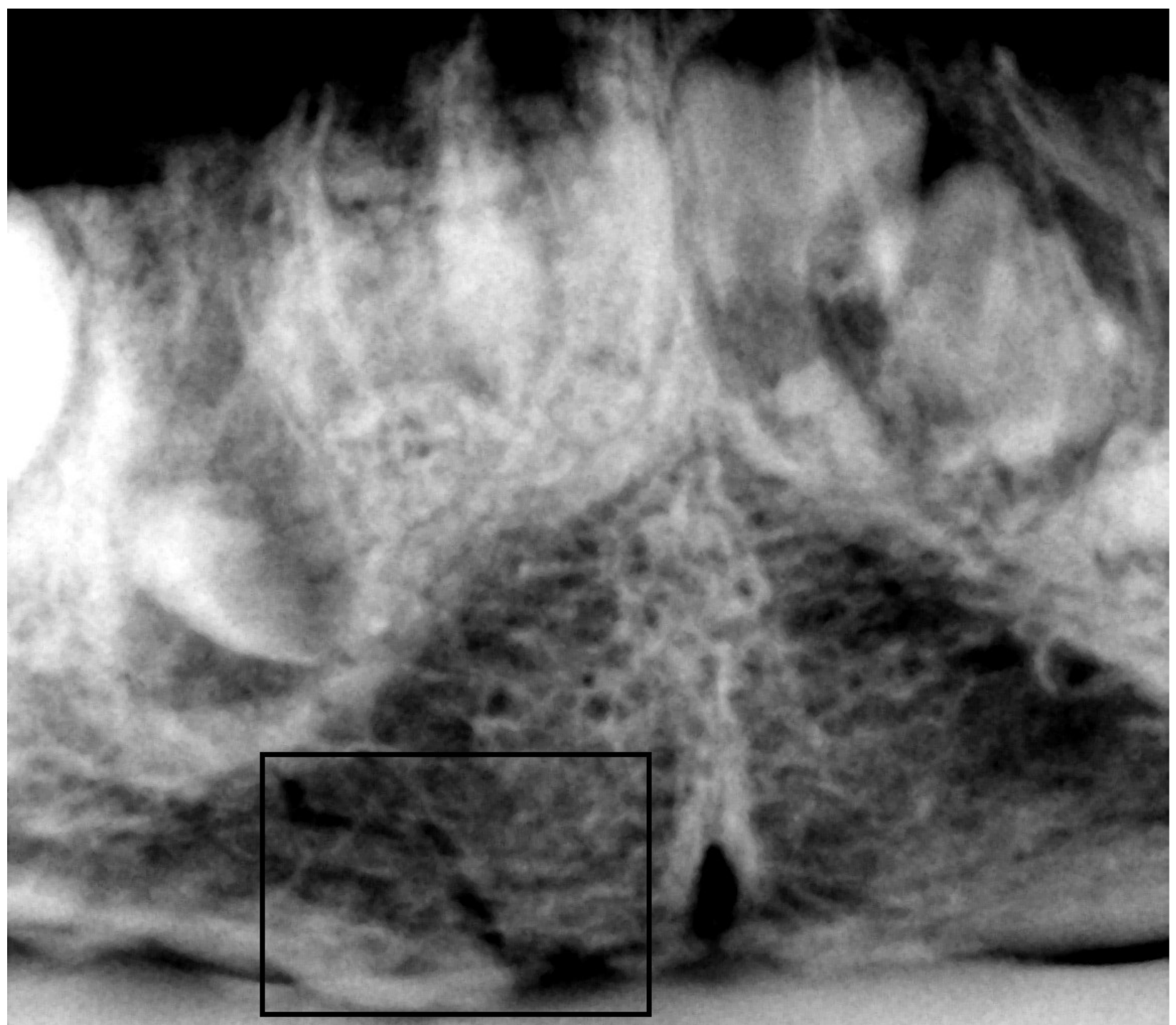

Fig. 5. Radiograph of mandible of Individual 66-2, posterior to anterior plane. Box demarcates the cloaca running from the left permanent canine bud to the inferior mandibular border.

steal elevation prompting chronic inflammatory cells and proliferating fibroblasts to form reactive bone (Resnick, 2002). Mandibular bone is known for exuberant peripheral reactive bone formation, a feature that is rare in the maxilla (Betts et al. 1996). The appearance of periosteal reaction is determined by the intensity, aggressiveness, and duration of the underlying insult (Rana et al., 2009). The periosteum in children is more active and less adherent to the cortex than in adults. Thus, periosteal reaction can occur earlier and appear more aggressive in children than in adults (Rana et al., 2009). In individual 66-2 the reactive periosteal bone exhibits a laminated and separated pattern, suggesting alternating periods of reaction that were more or less aggressive. In sum, for infant number 66-2 from the site of Shamanka II, the macroscopic and radiological appearance of the mandibular lesion is most consistent with a tooth-germ related purulent osteomyelitic infection with concomitant new periosteal bone formation.

\section{DISCUSSION}

\section{Etiology}

While not frequently noted, osteomyelitis of the mandible has been documented in a range of archaeological skeletal samples (Roney, 1966; Gregg and Gregg, 1987; Khudaverdyan, 2011). At 
Shamanka II osteomyelitic lesions are rare (Lieverse, 2010); no other individuals from this site, nor from others in the same area and timeperiod, had osteomyelitis of the jaws. Today osteomyelitis of the jaw is common enough to warrant categorization as a distinct clinical entity, however, the appearance of the lesion in individual 66-2, and the proposed source and route of infection are rare (Baltersperger and Eyrich, 2009). Most osteomyelitic infections of the jaws arise from carious or periodontal infections, with dental biofilm recognized as a possible but less likely option (Brady et al., 2006). Osteomyelitis can arise secondarily, spread to the jaws hematogeneously, but this is unlikely in this case as the cloaca pinpoints the infection location and none of the other bones have lytic lesions. The location of the cloaca, arising off the forming left permanent mandibular canine, and the lack of caries or vertical or horizontal alveolar bone loss, suggest that oral microorganisms were responsible for the infection.

Clearly, the microorganisms responsible for infection in this individual will not be preserved so it is not possible to isolate and identify specific bacteria. However, oral bacterial genera that have been implicated in osteomyelitis in the jaws of children are: Staphylococcus (especially $S$. aureus), Streptococcus, Actinomyces, and Enterococcus (Zbinden, 2009). Anaerobic bacteria include Gram-positive and negative cocci and Gramnegative rods (Zbinden, 2009). Normal healthy oral flora also have the potential for pathological effects (Willet et al., 1991); approximately 700 bacterial species have been identified in the human oral cavity (Aas et al., 2006), although a healthy individual will have a limited number in their oral cavity at any one time (Zbinden, 2009).

While it is well documented that huntergatherer and agricultural populations experience a different suite of infections from each other because of differences in population size and density (Armelagos and McArdle, 1975; Dobson and Carper, 1996), infections resulting from dental biofilm may be similar as they are likely not affected by these population parameters. Furthermore, oral microorganisms have great antiquity (Schultz, 1956; Caufield et al., 2007). However, it is not well known what effect diet has on the types, prevalence, and degree of pathogenicity of oral microorganisms that cause osteomyelitis. Analysis of a recent hunter-gatherer group from
Central Africa found high diversity in oral microbial communities and many previously unreported genera (Nasidze et al., 2011) suggesting the human oral cavity can harbour population specific microbiomes of substantial diversity. As well, fish-based diets have been shown to expose humans to a unique range of pathogens (Novotny, 2004). Thus, it is possible the hunterfisher-gatherer people of the Lake Baikal area had a rather distinctive oral environment. Although, given the rarity of osteomyelitis of the jaws, it is not expected that they experienced an abnormal level of pathogenicity. Future research should investigate if markers of oral bacteria in dental calculus can be identified in Cis-Baikal huntergatherers, as has been done with some success in ancient and modern hominins (Moorer et al., 1993; Arensburg, 1996). Furthermore, research that explores the range of variation in oral bacteria between groups with different subsistence patterns could be very useful in improving our understanding of the causes of dental disease.

It is also important to consider that breastfeeding can inhibit Staphylococcus and Streptococcus infection (Welsh and May, 1979). Stable nitrogen isotope $\left(\delta^{15} \mathrm{~N}\right)$ values of bone collagen samples are used to determine the breastfeeding status of subadults. The $\delta^{15} \mathrm{~N}$ value of individual $66-2$ is elevated suggesting breast-milk was still a major source of protein. This is in keeping with a mean age of complete weaning of three to four years in the Shamanka II sample (Waters-Rist et al., 2011). The fact that the infant did not succumb to acute infection, but rather survived into the period of chronic infection whereby a distinctive bony lesion was formed, may have been partially the result of the immune boosting effects of breastfeeding. Ultimately however, the osteomyelitic infection was likely the cause of death in this infant. Osteomyelitis of the mandible is frequently associated with bacteraemia, which can be lethal (Aufderheide and Rodriguez-Martin, 1998).

\section{CONCLUSION}

An infant from a 7,000-year-old archaeological site in Siberia presented with a mandibular lesion most consistent with a diagnosis of osteomyelitis with periosteal new bone, arising from infection of the canine tooth germ possibly from normally non-pathogenic oral bacteria. This case study extends the time depth of our knowledge of osteo- 
osteomyelitis of the jaw and highlights a rather rare infection source and route.

\section{ACKNOWLEDGMENTS}

Mr. Vladimir Evanovich Bazaliiskii is acknowledged as a participating investigator, being the director of archaeological excavations at Shamanka II, and the steward of the human skeletal material. Dr. Dan Temple is thanked for taking radiographs. Thank you to the editor and anonymous reviewers for their astute comments and questions which improved this manuscript.

\section{LITERATURE CITED}

Aas JA, Paster BJ, Stokes LN, Olsen I, Dewhirst FE. 2005. Defining the normal bacterial flora of the oral cavity. J Clin Microbiol 43:5721-5732.

Arensburg B. 1996. Ancient dental calculus and diet. Human Evolution 11(2):139-145.

Armelagos GJ, McArdle A. 1975. Population, disease, and evolution. In: Population studies in archaeology and biological anthropology: A symposium, Swedlund AC, editor. Volume 30, Memoirs of the Society for American Archaeology: p. 1-10.

Aufderheide AC, Rodriguez-Martin C. 1998. The Cambridge Encyclopedia of paleopathology. UK: Cambridge University Press.

Baltensperger M, Eyrich G. 2009. Osteomyelitis of the jaws: definition and classification. In: Baltensperger M, Eyrich G, editors. Osteomyelitis of the jaws. Berlin: Springer-Verlag. p. 5-56.

Baltensperger M, Grätz K, Bruder E, Lebeda R, Makek M, Eyrich G. 2004. Is primary chronic osteomyelitis a uniform disease? Proposal of a classification based on a retrospective analysis of patients treated in the past 30 years. J Cranio-Maxillofac Surg 32:43-50.

Baranoff A. 1934. Incidence of osteomyelitis of jaw bones among Chinese. Chinese Medical Journal 48:638.

Baratti-Mayer D, Pittet B, Montandon D, Bolivar I, Bornand JE, Hugonnet S, Jaquinet A, Schrenzel J, Pittet D. 2003. Noma: an "infectious" disease of unknown aetiology. The Lancet Infectious Diseases 3(7):419-431.

Bazaliiskii VI. 2010. Mesolithic and Neolithic complexes in the Baikal region. In: Weber AW, Katzenberg MA, Schurr TG, editors. Prehistoric hunter-gatherers of the Baikal region,
Siberia: bioarchaeological studies of past lifeways.Pennsylvania: University of Pennsylvania Museum Press. p. 51-86.

Belli E, Matteini C, Andreano T. 2002. Sclerosing osteomyelitis of Garré periostitis ossificans. J Craniofac Surg 13(6):765-768.

Betts NJ, Abaza NA, Kazemi A.1996. An expansile bony lesion of the posterior mandible in a 12 year old girl. J Oral Maxillofac Surg 54:203209.

Brady BA, Leid JG, Costerton JW, Shirtliff ME. 2006. Osteomyelitis: clinical overview and mechanisms of infection persistence. Clin Microbiol Newsletter 28:65-72.

Bruder E, Jundt G, Eyrich G. 2009. Pathology of osteomyelitis. In: Baltensperger M, Eyrich G, editors. Osteomyelitis of the Jaws. Berlin: Springer-Verlag. p. 121-133.

Caffey J, Silverman WA. 1945. Infantile cortical hyperostosis. Preliminary report of a new syndrome. Am J Roentgeno 154:1-16.

Caufield PW, Sabena D, Fitch D, Li Y.2007. Population structure of plasmid-containing strains of Streptococcus mutans, a member of the human indigenous biota. J Bacteriol189 (4):12381243.

Chaudhary S, Kalra N, Gomber S. 2004. Tuberculosis osteomyelitis of the mandible: A case report in a 4-year-old child. Oral Surg Oral Med Oral Pathol Oral Radiol Endod 97:603-606.

Cierny G, Mader JT, Penninck J. 1985. A clinical staging system of adult osteomyelitis. Contemp Orthop 10(5):17-37.

Dobson AP, Carper RE. 1996. Infectious diseases and human population history. Bioscience 46(2):115-126.

Enwonwu CO, Falkler WA, Idigbe EO. 2000. Orofacial gangrene (noma/cancrum oris): pathogenetic mechanisms. Crit Rev Oral Biol Med 11(2):159-171.

Erasmus JH, Thompson IO, van der Westhuijzen AJ. 1998. Tuberculous osteomyelitis of the mandible: Report of a case. J Oral Maxillofac Surg 56:1355-1358.

Felsberg GJ, Gore RL, Schweitzer ME, Jui V. 1990. Sclerosing osteomyelitis of Garre (periostitis ossificans). Oral Surg Oral Med Oral Pathol 70:117-120.

Gadgil RM, Bhoosreddy AR, Padhyay BR. 2012. Osteomyelitis of the mandible leading to pathological fracture in a tuberculosis patient: 
A case report and review of literature. Ann Trop Med Public Health 5(4):383-386.

Gonçalves M, Oliveira DP, Oya EO, Gonçalves A. 2002. Garre's osteomyelitis associated with a fistula: a case report. J Clin Pediatr Dent 26:311 -314 .

Gregg JB, Gregg PS. 1987. Dry bones: Dakota territory reflected. Sioux Falls, South Dakota: Sioux Printing, Inc.

Gupta M, Singh M. 2007. Primary tuberculosis of the mandible. Indian Pediatr 44: 53-54.

Hershkovitz I, Donoghue HD, Minnikin DE, Besra GS, Lee OY-C, Germaey AM, Galili E, Eshed V, Greenblatt CL, Lemma E, Bar-Gal GK, Spigelman M, Ahmed N. 2008. Detection and Molecular Characterization of 9,000-Year-Old Mycobacterium tuberculoisis from a Neolithic Settlement in the Eastern Mediterranean. PLoS ONE 3(10).

Huang GTJ. 2009. Endodontic infections in incompletely developed teeth. In: Fouad AF, editor. Endodontic microbiology. Iowa: WileyBlackwell. p. 261-280.

Kapur V, Li LL, Iordanescu S, Hamrick MR, Wanger A, Kriswirth BN, Musser JM. 1994. Characterization by automated DNA sequencing of mutations in the gene (rpoB) encoding the RNA polymerase 3 subunit in rifampinresistant mycobacterium tuberculosis from New York City and Texas. Journal of Clinical Microbiology 32(4):1095-1098.

Katzenberg MA, Bazaliiskii VI, Goriunova OI, Savelev NA, Weber AW. 2010. Diet reconstruction of prehistoric hunter-gatherers in the Lake Baikal region. In:Weber AW, Katzenberg MA, Schurr TG, editors. Prehistoric huntergatherers of the Baikal region, Siberia: bioarchaeological studies of past lifeways.Pennsylvania: University of Pennsylvania Museum Press. p. 175-192.

Khudaverdyan AY. 2011. The Anthropology of Infectious Diseases of Bronze Age and Early Iron Age from Armenia. Dental Anthropology 24 (2-3):42-54.

Lew DP, Waldvogel FA. 2004. Osteomyelitis. Lancet 364: 369-379.

Lewis ME. 2011. Tuberculosis in the non-adults from Romano-British Poundbury Camp, Dorset, England. International Journal of Paleopathology 1:12-23.
Lewis ME, Gowland R. 2009. Infantile cortical hyperostosis: cases, causes and contradictions. Proceedings of the Ninth Annual Conference of the British Association for Biological Anthropology and Osteoarchaeology, Department of Archaeology, University of Reading. 2007. BAR International Series 1918. Oxford: Archaeopress.

Lieverse AR.2010. Health and behaviour in the mid-Holocene Cis-Baikal: biological indicators of hunter-gatherer adaptation and cultural change. In: Weber AW, Katzenberg MA, Schurr TG, editors.Prehistoric hunter-gatherers of the Lake Baikal region, Siberia: bioarchaeological studies of past lifeways. Pennsylvania: University of Pennsylvania Museum Press. p. 135-174.

Liversidge HM.2003. Variation in modern human dental development. In: Thompson JL, Krovitz GE, Nelson AJ, editors. Patterns of growth and development in the genus Homo. Cambridge: Cambridge University Press. p. 73-113.

Liversidge HM, Molleson T.2004. Variation in crown and root formationand eruption of human deciduous teeth. Am J Phys Anthropol 123:172-180.

MacLachlan AK, Gerrard JW, Houston CS, Ives EJ. 1984. Familial infantile cortical hyperostosis in a large Canadian family. Can Med Assoc J 130: 1172-1174.

Marx RE. 1991. Chronic osteomyelitis of the jaw.Oral Maxillofac Surg Clin North Am 3(2):367-81.

Mercuri LG. 1991. Acute osteomyelitis of the jaws. Oral Maxillofac Surg Clin North Am 3(2): 355366.

Messner RP. 1987. Arthritis por micobacterias y hongos (Arthritis due to mycobacteria and fungi). In Arthritis y Orras Patologias Relacionadas.Volume 4, 10 ${ }^{\text {th }}$ ed, Arthritis and Applied Pathological Conditions. McCarty DJ, editor. Panamericana: Madrid. p. 1698-1708.

Moorrees CFA, Fanning EA, Hunt EE. 1963a. Age variation of formation and resorption of threedeciduous teeth in children. Am J Phys Anthropol 21:205-213.

Moorrees CFA, Fanning EA, Hunt EE. 1963b. Age variation of formation stages for ten permanent teeth. J Dent Res 42:1490-1502. 
Moorer WR, Ten Cate JM, Buijs JF. 1993. Calcification of cariogenic Streptococcus and of Carynebacterium (Bacteriomeia)matruchotti. J Dent Res 72: 1021-1026.

Mukherjee KK, Kaushik R, Nada R, Khosla VK, Khanelwal N, Kak VK. 2002. Calvarial tuberculosis. Surgical Neurology 57:195-203.

Nasidze I, Li J, Schroeder R, Creasey JL, Li M, Stoneking M. High diversity of the saliva microbiome in Batwa Pygmies [Internet]. 2011 [cited 2012 November 19]; PLoS ONE 6(8): e23352. Available from: doi:10.1371/ journal.pone.0023352

Novotny L, Dvorska L, Lorencova A, Beran V, Pavlik I. 2004. Fish: a potential source of bacterial pathogens for human beings. Vet Med Czech 49(9):343-358.

Ortner DJ. 2003. Identification of pathological conditions in human skeletal remains. $2^{\text {nd }}$ ed. San Diego: Elsevier Academic Press.

Pálfi G, Bereczki1 Z, Ortner DJ, Dutour O. 2012. Juvenile cases of skeletal tuberculosis from the TerryAnatomical Collection (Smithsonian Institution,Washington, D.C., USA). Acta Biologica Szegediensis 56(1):1-12.

Rana RS, Wu JS, Eisenberg RL. 2009. Periosteal reaction. Am J Roentgenol 193(4):259-272.

Resnick D. 2002. Osteomyelitis, septic arthritis, and soft tissue infection: mechanisms and situations. In: Resnick D, editor. Diagnosis of bone and joint disorders. $4^{\text {th }}$ ed. Philadelphia: WB Saunders Company. p. 2377-2480.

Roberts C, Manchester K. 2010. The archaeology of disease, $3^{\text {rd }}$ ed. UK:The History Press.

Rodriguez Cordiero MM, de Carvalho Rocha MJ. 2005. The effects of periradicular inflammation and infection on a primary tooth and permanent successor. J Clin Pediatr Dent 29(3):193200.

Roney Jr J. 1966. Paleoepidemiology: an example from California. In: Jarcho S, editor. Human paleopathology. New Haven: Yale University Press.p. 99-107.

Schultz AH. 1956. The occurrence and frequency of pathological and teratological conditions and of twinning among non-human primates. Primatologica 1:965-1014.

Slootweg PJ. 2010. Bone Diseases of the Jaw. Int J Dent: doi:10.1155/2010/702314.
Thijn CJP, Steensma JT. 1990. Tuberculosis of the Skeleton: Focus on Radiology. New York:Springer-Verlag.

Waters-Rist AL, Bazaliiskii VI, Weber A, Katzenberg MA. 2011. Infant and child diet in Neolithic hunter-fisher-gatherers from Cis-Baikal, Siberia: intra-long bone stable nitrogen and carbon isotope ratios. Am J Phys Anthropol 146(2):225-241.

Weber AW, McKenzie HG, Beukens R.2010. Radiocarbon dating of Middle Holocene culture history in Cis-Baikal. In: Weber AW, Katzenberg MA, Schurr TG, editors. Prehistoric hunter-gatherers of the Baikal region, Siberia: bioarchaeological studies of past lifeways. Pennsylvania: University of Pennsylvania Museum Press. p. 27-49.

Welsh J K, May JT. 1979. Anti-infective properties of breast milk. J Pediatr 94(1):1-9.

Wilensky AO. 1932. Osteomyelitis of the jaws. Arch Surg 25(1):183-237.

Willet NP, White RR, Rosen S. 1991. Essential dental microbiology. Norwalk: Appleton and Lange.

Zbinden R. 2009. Microbiology. In: Baltensperger M, Ryrich G, editors. Osteomyelitis of the Jaws. Berlin: Springer-Verlag. p. 135-143. 